\title{
Immediate Stenting VS Deferred Stenting In Patients With ST-Segment Elevation Myocardial Infarction Treated With Primary Percutaneous Coronary Intervention
}

\author{
Malleswara Rao Dangeti, Raghu Kishore Galla, Ravi Kiran
}

\section{INTRODUCTION}

Timely primary percutaneous coronary intervention (PPCI) with balloon dilatation and stent implantation is the standard treatment for patients with ST-segment elevation myocardial infarction (STEMI) [1,2]. However, a patent infarct related artery does not necessarily translate into a good myocardial perfusion. In spite of PPCI, some patients still develop reduced coronary blood flow, despite a patent epicardial vessel, a complication thatis associated with impaired prognosis $[3,4]$. An alternative strategy of delaying or deferring stent implantation, after a stable blood flow has been secured in the infarct-related artery, could preserve coronary blood flow and reduce the risk of embolization, and thereby potentially improve clinical outcome [5-9]. We report a case of deferred stenting in a patient presented with inferior wall ST-segment elevation myocardial infarction (IWMI).

\section{Case Report}

A 52-years old male patient presented to the emergency department (ED) with complaining of continuous chest pain for 10 hours and giddiness for 4 hours. The patient had been in his usual health, until approximately 8:30 on the morning of admission, when he developed suddenonset severe chest pain at rest. The pain was retrosternal, was crushing type, and was associated with profuse sweating. The pain did not worsen with inspiration and was associated with shortness of breath. Prior history was not significant for the related risk factors as hypertension, diabetes, dyslipidemia, family history of MI; except he was smoking excessively for a long duration.

On physical examination, cardiac sounds were normal on auscultation. His blood pressure was 100/60mm Hg

Article received on 24 APR 2017, published on 30 APR 2017.

Malleswara Rao Dangeti ${ }^{1}$, Raghu Kishore Galla ${ }^{1}$, Ravi Kiran ${ }^{1}$,

${ }^{1}$ Senior Resident, Department of Cardiology, NIMS, India

Corresponding author: MalleswaraRao Dangeti

Email: ramakrishnaji83@gmail.com and heart rate was $40 \mathrm{bpm}$.Initial ECG showed complete heart block (CHB) with ST-segment elevation (STE) in leads II, III, AVF and V4R and ventricular escape rhythm of 40 for a minute(Fig 1).

Fig 1: ECG showing complete heart block (chb) at presentation (a), paced rhythm after inserting tpi(b), normal sinus rhythm five days after index procedure

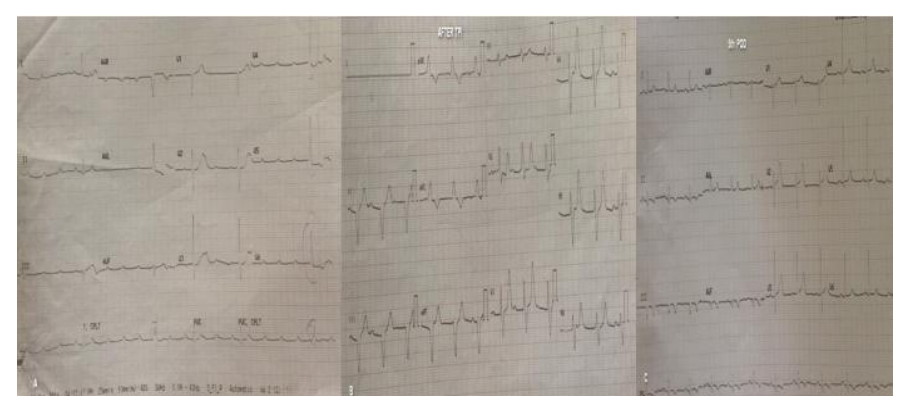

Posterior wall ECG did not show any significant findings. Transthoracic echocardiography (TTE) revealed hypokinesia of the inferior wall with a left ventricular ejection fraction (EF) of $50 \%$ and there was no intracardiac thrombosis, VSD or MR.

Before catheterization, the patient received a loading dose of aspirin $325 \mathrm{mg}$ oral, prasugrel $60 \mathrm{mg}$ oral and atorvastatin $80 \mathrm{mg}$ oral. After due consent taken from patient, he was immediately taken to the catheterization laboratory. Temporary pacing wire was insertedand placed at a rate of $60 \mathrm{bpm}$. Coronary angiogram was performed at the same time. Coronary angiography revealed that the right coronary artery (RCA) was acutely and totally occluded at the mid-portion. Left system injection showedmid-70\% segmental stenosis in the left anterior descending artery (LAD). There was milddisease of the left circumflex artery (LCX) which was a non-dominant vessel. We planned adhoc PTCA to culprit vessel. RCA mid occlusion was crossed by a floppy guidewire and serial pre-dilatation was performed with a short semi-compliant balloon. We then 
performed thrombectomy and retrieved a large, red thrombus. Intracoronary loading dose of Tirofiban was administrated according to the patient's body weight. The thrombolysis in myocardial infarction (TIMI) flow of the RCA improved from 0 to II. However, RCA had huge thrombus burden despite above measures (Fig 2).

Fig 2: CAG showing proximal occlusion of RCA (a) and thrombo suction during index procedure (b) and final injection showing high thrombus burden despite thrombo suction and balloon dilatation

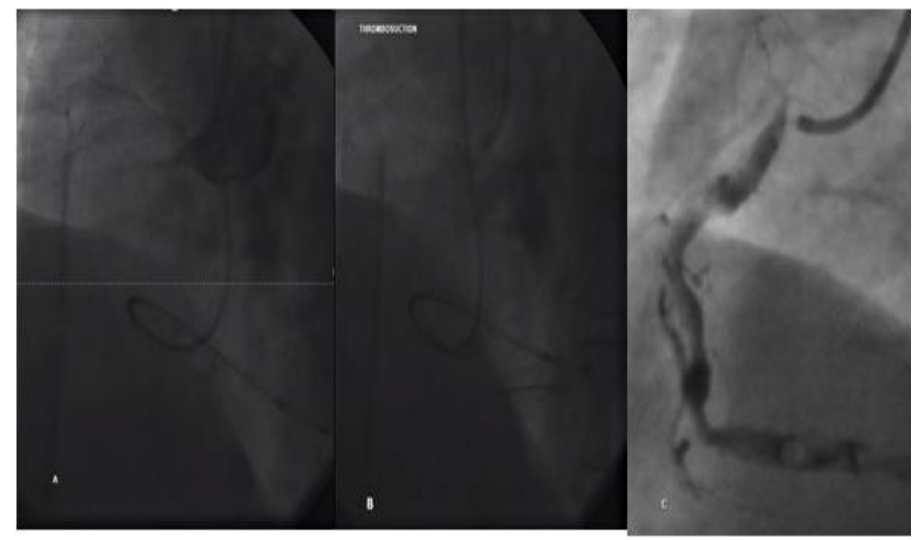

\section{DEBATE}

\section{IMMEDIATE STENTING STRATEGY}

Although primary PCI many a time restores normal epicardial coronary flow in STEMI, suboptimal myocardial perfusion-low-/no-reflow phenomenon or microvascular obstruction (MVO)-occurs in around two thirds of patients $[10,11]$. Immediate stenting (IS) in highly prothrombotic and inflammatory milieu of infarct-related arteries (IRAs) during primary PCI would increase distal embolization of clot and athermanous plaque debris and provoke the inflammation process [28-32]. The prognostic importance of no-reflow during PCI parallels its close relationship to mortality and morbidity ${ }^{12}$.MVO may be clinically silent or may present as refractory hypotension, myocardial infarction, cardiogenic shock and death.

The major pathophysiology of MVO is distal embolization among various mechanisms, including reperfusion injury, infarct tissue edema, in situ thrombosis, and microvascular spasm[13,14].Distal embolization occurs in approximately $5-10 \%$ of patients with STEMI treated with primary PCI and is often associated with an increased risk of reinfarction and development of heart failure[15,16]. The risk is particularly high in selected patients with a high thrombus burden; therefore, removal of the thrombus formation or part of it by mechanical or manual thrombectomy has been considered a potential solution.Thrombectomy of late has been proven no benefit, (though initial trials like TAPAS showed some promise, however the largest and latest registry total showed no decrease in infarct size and mortality; however an increase in stroke incidence was noted) [1719]. Even thoughadditional intracoronary administration of adenosine resulted in a significant improvement of MVO during PPCI in REOPEN-AMI study; larger trials are needed to justify it [20]. Hence, DS can be considered as a better option in such kind of lesions.

\section{DEFERRED STENTING STRATEGY}

Deferred stenting (DS) reduces the risk of 'no-reflow' and increases myocardial salvage compared with immediate stenting [21-25]. Maximum stent diameter and length are both larger, indicating that the vessel dimensions will increase, likely due to attenuation of coronary artery tone with time from reperfusion [26]. However, the deferred strategy presents enormous issues in terms of cost and potential bleeding risk. Although prolonged GP IIb/IIIa use plays some role in dissolving thrombus, on the contrary, the extra antithrombotic therapy is negative because invariably it leads to increased bleeding. Another safety concern around DS is theoretical time related risk of coronary reocclusion and its consequences.Even social issues of a patient having negative outcomes despite a procedure being done are difficult to tackle practically especially in young patients. It is wise to have allow threshold for use of IABP in DS as it helps to maintain optimal perfusion to infracted area and also gives therapeutic safety edge in case emergency intervention needed [27].In conclusion, DS strategy is double edged sword with the possibly lesser risk of no reflow, however at the expense of risk of re-occlusion, which could be life threatening in certain scenarios.

\section{HEAD TO HEAD TRAILS}

Registry data suggest that DS could preserve coronary blood flow and reduce the risk of embolization, and 
thereby potentially improve clinical outcome [28-37]. In a pilot study by Kelbaek $\mathrm{H}$ et al., DS reduced thrombus burden and increased myocardial salvage in patients with STEMI [38]. DS had fewer major cardiac events at 6 months compared to IS in a study by Tang et al [19]. In a meta-analysis, Freixa and colleagues concluded trend towards improved angiographic outcome in patients treated with DS [39]. DS did not reduce the occurrence of death, heart failure, myocardial infarction, or repeat revascularization compared with IS in DANAMI 3DEFER study [40]. The major limitation of this study is that the trial did not select patients who were at the highest risk for developing MVO. In the majority of previous studies, untoward ischemic events and significant bleeding are infrequent in the interval between index reperfusion and actual stent implantation [21-25].

Fewer patients in the deferred stenting group had no/slow-reflow, no reflow and intra-procedural thrombotic events in DEFER STEMI study [41]. TIMI flow grades at the end of PCI were higher in the DS group. IS technique used in DEFER STEMI may have increased MVO because high rates of pre and post-dilatation were used compared with DS (57.7\% versus $71.4 \%$ ). Such balloon dilatation is necessary to avoid stent under expansion. But additional balloon dilatation may also increase the risk of MVO through distal embolization of thrombotic material. This might have had a confounding effect to explain the higher rate of angiographic slow-reflow in the IS group in this study. DS did not significantly reduce infarct size and the incidence of MVO compared with IS in INNOVATION study [42]. Paradoxically, there was a non-significant trend toward lower microvascular obstruction in IS group compared with DS group in The MIMI Study [43]. Again, no difference in 6-month outcomes was apparent for the rate of major cardiovascular and cerebral events in above study. These results completely rebut the promising findings of preliminary studies that suggested deferred stenting should translate to clinical benefit. In-fact MVO is not exclusive to immediate stenting group, defer stent group withpre-dilation or thrombosuction are also likely to have distal embolization. Hence, better solution theoretically for this problem is meshed stents (MGUARD), which trap the thrombotic muck, though $1^{\text {ST }}$ generation of these stents didn't show any benefit over routine DES, however results with $2^{\text {nd }}$ generation meshed stents are awaited and they hold a promise for future [44].

DS is therefore selectively advocated in subset of patients who are at increased risk of MVO such as increased age (i.e., 65 years of age or older), duration of symptoms $>6 \mathrm{~h}$; heavy thrombus burden (TIMI grade 2 or higher), long lesion length $(>24 \mathrm{~mm})$, small vessel diameter (i.e., $<2.5 \mathrm{~mm}$ ), and clinical signs of acute microvascular injury after initial reperfusion with persistent ST-segment elevation $>50 \%$ [25-29]. Is preferred over DS when the patient has cardiogenic shock, STEMI with Killip class III-IV or presenting as ventricular fibrillation, or sustained ventricular tachycardia and RVMI because the prognosis is very bad with these cases. STEMI patients with poor distal TIMI flow (0/1) despite adequate Predilatation and thrombosuction are also ideal candidates for DS because stenting with no distal runoff is dangerous and is a nidus for acute stent thrombosis. This is one such scenario where even BMS may be preferred over DES if at all we suspect vessel recoil to scaffold the vessel. Special subsets like young smokers with single vessel disease with less than $50 \%$ lesion after thrombosuction and those patients with residual lesions with negative FFR after thrombosuction and Predilatation may not need immediate stenting even though they are at low risk for MVO. STEMI patients with LM disease with low SYNTAX score will benefit from IS although those with high SYNTAX score may be left with no stenting and should be sent for emergency CABG.TVD cases with high SYNTAX score may benefit from deferring strategy, because long term PCI outcomes are poor compared to surgery and immediate priority is to restore flow in culprit artery(even in this scenario giving a waiting period of few minutes and checking for reclosure of vessel after wire is also removed may be helpful to assess behaviour of vessel and predict complications).However such patients have to be considered for early surgery. DS should not be adopted whenever there is coronary dissection following reperfusion, cardiac conditions requiring emergent or urgent surgical repair, failed thrombolysis and rescue PCI, and high risk of bleeding.

\section{WHAT WE DID}

As the patient presented late (approximately 10 hours) and RCA having a huge burden of thrombus despite 
thrombectomy, repeat coronary angiography with the intention to implant a stent in RCA (deferred strategy) was scheduled about 36 hours later. We came out with minimalist immediate mechanical intervention (MIMI). The patient was given an intravenous glycoprotein $\mathrm{IIb} / \mathrm{III}$ inhibitor (24 h infusion with Tirofiban). He also received intravenous high molecular weight heparin (UFH $60 \mathrm{U} / \mathrm{kg}$ every $6 \mathrm{~h}$ ) for 36 hours.

After 36 hours, he was again taken to the catheterization laboratory. A 7-French Judkins right (JR) 3.5 guide catheter (Cordis) was inserted through right common femoral access. Right coronary injection demonstrated decreased thrombus burden with residual $70 \%$ stenosis. ChoICE Floppy (Boston Scientific) guide-wire was used to navigate through the index lesion. The lesion was Predicated with $1.25 \times 16 \mathrm{~mm}$ Sprinter ${ }^{\circledR}$ Legend semicompliant balloon (Medtronic, Inc.) followed by $2 \times 10$ mm balloon. We took a $2.75 \times 28 \mathrm{~mm}$ Youkon Choice (Translumina Therapeutics LLP) drug-eluting stent and deployed it at 10 atmospheres (atm). After completion of the procedure, angiographic appearance of the stent was excellent, with the restoration of TIMI-3 flow (Fig3). The patient had normal sinus rhythm on $5^{\text {th }}$ day of index procedure.

Fig 3- CAG showing timi 2 flow with dramatically decreased thrombus burden and (c) and optimum results after stenting $(\mathrm{d})$

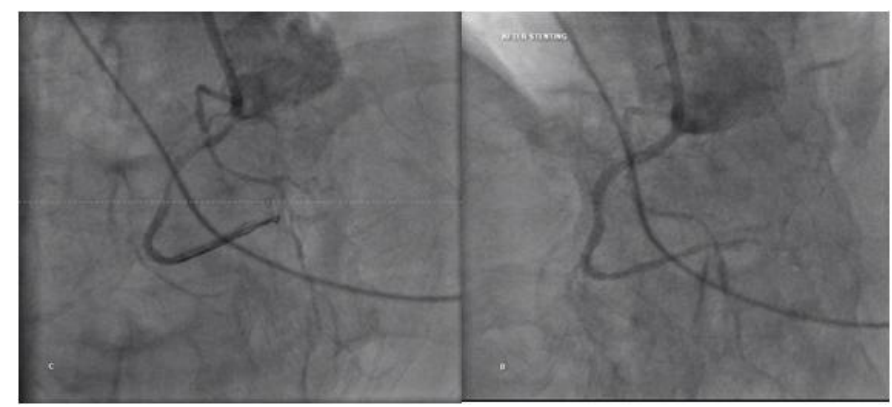

\section{CONCLUSION}

Deferring stenting in acute MI cannot be considered cardioprotective strategy, however, can be considered in selected group to lower the routine anticipated complications in primary interventions. More studies in larger subset of patients rather than single case report will be beneficial in drawing major conclusions and in formulating general practice guidelines in such cases.
Abbreviation:

TTE - Transthoracic echocardiography

IWMI - Inferior wall ST segment elevation myocardial infarction

CHB - Complete heart block

STE - ST segment elevation

EF - Ejection fraction

RCA - Right coronary artery

ED - Emergency department

LAD - Left anterior descending artery

LCX - Left circumflex artery

DS - Deferred stenting

IS - Immediate stenting

PPCI - Primary percutaneous intervention

PCI - Percutaneous intervention

IABP - Intra-aortic Balloon Pump

\section{REFERENCES}

1. Windecker S, Kolh P, Alfonso F, et al, for the Task Force on Myocardial Revascularization of the European Society of Cardiology (ESC) and the European Association for Cardio-Thoracic Surgery (EACTS). 2014 ESC/EACTS guidelines on myocardial revascularization. Eur Heart J 2014; 35: 2541-619.

2. O'Gara PT, Kushna FG, Ascheim DD, et al. 2013 ACCF/AHA Guideline for the management of STelevation myocardial infarction: executive summary: a report of the American College of Cardiology Foundation/American Heart Association Task Force on Practice Guidelines. Circulation 2013; 127: 529-55.

3. Jaff e R, Charron T, Puley G, Dick A, Strauss BH. Microvascular obstruction and the no-reflow phenomenon after percutaneous coronary intervention. Circulation 2008; 117: 3152-56.

4. Henriques JP, Zijlstra F, Ottervanger JP, et al. Incidence and clinical significance of distal embolization during primary angioplasty for acute myocardial infarction. Eur Heart J 2002; 23: 1112-17.

5. Cafri C, Svirsky R, Zelinher J, et al. Improved procedural results in coronary thrombosis are obtained with delayed percutaneous coronary interventions. J Invasive Cadiol 2004; 16: 69-71. 
6. Isaaz K, Robin C, Cerisier A, et al. A new approach of primary angioplasty for ST-elevation acute myocardial infacrtion based on minimalist immediate mechanical intervention. Coron Artery Dis 2006; 17: 261-69.

7. Meneveau N, Séronde MF, Descotes-Genon V, et al. Immediate versus delayed angioplasty in infarct-related arteries with TIMI III flow and ST segment recovery: a matched comparison in acute myocardial infarction. Clin Res Cardiol 2009; 98: 257-64.

8. Tang L, Zhou SH, Hu XQ Fang ZF, Shen XQ. Eff ect of delayed vs immediate stent implantation on myocardial perfusion and cardiac function in patients with ST-segment elevation myocardial infarction undergoing primary percutaneous intervention with thrombus aspiration. Can J Cardiol 2011; 27: 541-47.

9. Ke D, Zhong W, Fan L, Chen L. Delayed versus immediate stenting for the treatment of ST-elevation acute myocardial infarction with a high thrombus burden. Coron Artery Dis 2012; 23: 497-506.

10. Niccoli G, Burzotta F, Galiuto L, Crea F. Myocardial no-reflow in humans. J Am Coll Cardiol. 2009; 54:281292. Doi: 10.1016/j.jacc.2009.03.054.

11. Nijveldt R, Beek AM, Hirsch A, Stoel MG, Hofman MB, Umans VA, AlgraPR, Twisk JW, van Rossum AC. Functional recovery after acute myocardialinfarction: comparison between angiography, electrocardiography, and cardiovascular magnetic resonance measures of micro vascular injury. J Am Coll Cardiol. 2008; 52:181189. Doi: 10.1016/j.jacc.2008.04.006.

12. Maritime I, Some T, Okumura $\mathrm{K}$, et al. Angiographic No-reflow phenomenon as a predictor of adverse long term outcome in patients treated with percutaneous transluminal coronary angioplasty for first acute myocardial infarction. J Am Coll Cardiol 2000; 36(4):1202-9.

13. Jaffe R, Charron T, Puley G, Dick A, Strauss BH. Microvascular obstruction and the no-reflow phenomenon after percutaneous coronary intervention. Circulation. 2008; 117:3152-3156. Doi: 10.1161/ CIRCULATIONAHA.107.742312.
14. Bakers SC, Yazdani SK, Virmani R, Waltenberger J. Microvascular obstruction: underlying pathophysiology and clinical diagnosis. J Am CollCardiol. 2010;55:16491660. doi: 10.1016/j.jacc.2009.12.037.

15. Fokkema ML, Vlaar PJ, Svilaas T, et al. Incidence and clinical consequences of distal embolization on the coronary angiogram after percutaneous coronary intervention for ST-elevation myocardial infarction. Eur Heart J 2009; 30: 908-15.

16. Lønborg J, Kelbæk H, Helqvist S, et al. The impact of distal embolization and distal protection on long-term outcome in patients with ST elevation myocardial infarction randomized to primary percutaneous coronary intervention-results from a randomized study. Eur Heart J Acute Cardiovasc Care 2015; 4: 18088.

17. Fröbert $\mathrm{O}$, Lagerqvist $\mathrm{B}$, Olivecrona $\mathrm{GK}$, et al. Thrombus aspiration during ST-segment elevation myocardial infarction. N Engl J Med 2013; 369: 1587-97.

18. Jolly SS, Cairns JA, Yusuf S, et al. Randomized trial of primary PCI with or without routine manual thrombectomy. N Engl J Med 2015; 372: 1389-98.

19. Vlaar PJ, Svilaas T, van der Horst IC, et al. Cardiac death and reinfarction after 1 year in the Thrombus Aspiration during Percutaneous coronary intervention in Acute myocardial infarction Study (TAPAS): a 1-year follow-up study. Lancet 2008;371:1915-1920.

20. Niccoli G1, Rigattieri S, De Vita MR, Valgimigli M, Corvo P, Fabbiocchi F, Romagnoli E, De Caterina AR, La Torre G, Lo SchiavoP. Open-label, randomized, placebocontrolled evaluation of intracoronary adenosine or nitroprusside after thrombus aspiration during PCI for the prevention of micro vascular obstruction in AMI: the REOPEN-AMI. JACC CardiovascInterv. 2013 Jun;6(6):580-9.

21. Tang L, Zhou SH, Hu XQ, Fang ZF, Shen XQ. Effect of delayed vs immediate stent implantation on myocardial perfusion and cardiac function in patients with ST-elevation myocardial infarction undergoing primary percutaneous intervention with thrombus aspiration. Can J Cardiol 2011;27:541. 
22. Meneveau N, Seronde MF, Descotes-Genon V, et al. Immediate versus delayed angioplasty in infarct-related arteries with TIMI III flow and ST segment recovery: a matched comparison in acute myocardial infarction patients. Clin Res Cardiol 2009;98:257-64.

23. Cafri C, Svirsky R, Zelingher J, et al. Improved procedural results in coronary thrombosis are obtained with delayed percutaneous coronary interventions. J Invasive Cardiol 2004;16:69-71.

24. Isaaz K, Robin C, Cerisier A, et al. A new approach of primary angioplasty for ST-elevation acute myocardial infarction based on minimalist immediate mechanical intervention. Coron Artery Dis 2006;17:2619.

25. Di PP, Cannizzaro S, Parrinello G, et al. Is delayed facilitated percutaneous coronary intervention better than immediate in reperfused myocardial infarction? Six months follow up findings. J Thromb Thrombolysis 2006; 21:147-57.

26. Je Sang Kim, MD*; Hyun Jong Lee, MD*; CheolWoong $\mathrm{Yu}, \mathrm{MD}, \mathrm{PhD}$; Yang Min Kim, MD, PhD; Soon Jun Hong, MD, PhD Impact of Immediate Stent Implantation Versus Deferred Stent Implantation on Infarct Size and Microvascular Perfusion in Patients With STSegment- Elevation Myocardial Infarction. Circ CardiovascInterv. 2016;9:e004101.

27. Gu J, Hu W, Xiao H, Feng X, Chen Y, Zhang D. Intra-aortic balloon pump improves clinical prognosis and attenuates C-reactive protein level in acute STEMI complicated by cardiogenic shock. Cardiology. 2010;117(1):75-80.

28. Jaffe R, Charron T, Puley G, Dick A, Strauss BH. Microvascularobstruction and the no-reflow phenomenon after percutaneous coronary intervention. Circulation 2008;117:3152-6.

29. Morishima I, Sone T, Okumura K, et al. Angiographic no-reflow phenomenon as a predictor of adverse long-term outcome in patients treated with percutaneous transluminal coronary angioplasty for first acute myocardial infarction. J Am CollCardiol 2000;36:1202-9.
30. Antoniucci D, Valenti R, Migliorini A, et al. Direct infarct artery stenting without predilation and no-reflow in patients with acute myocardial infarction. Am Heart J 2001;142:684-90.

31. Ndrepepa G, Tiroch K, Keta D, et al. Predictive factors and impact of no reflow after primary percutaneous coronary intervention in patients with acute myocardial infarction. Circ Cardiovasc Interv 2010; 3: 27-33.

32. Harrison RW, Aggarwal A, Ou FS, et al., American College of Cardiology National Cardiovascular Data Registry. Incidence and outcomes of no-reflow phenomenon during percutaneous coronary intervention among patients with acute myocardial infarction. Am J Cardiol 2013;111:178-84.

33. Cafri C, Svirsky R, Zelinher J, et al. Improved procedural results in coronary thrombosis are obtained with delayed percutaneous coronary interventions. J Invasive Cadiol 2004; 16: 69-71.

34. Isaaz K, Robin C, Cerisier A, et al. A new approach of primary angioplasty for ST-elevation acute myocardial infacrtion based on minimalist immediate mechanical intervention. Coron Artery Dis 2006; 17: 26169.

35. Meneveau N, Séronde MF, Descotes-Genon V, et al. Immediate versus delayed angioplasty in infarct-related arteries with TIMI III flow and ST segment recovery: a matched comparison in acute myocardial infarction. Clin Res Cardiol 2009; 98: 257-64.

36. Tang L, Zhou SH, Hu XQ Fang ZF, Shen XQ. Eff ect of delayed vs immediate stent implantation on myocardial perfusion and cardiac function in patients with ST-segment elevation myocardial infarction undergoing primary percutaneous intervention with thrombus aspiration. Can J Cardiol 2011; 27: 541-47.

37. Ke D, Zhong W, Fan L, Chen L. Delayed verusus immediate stenting for the treatment of ST-elevation acute myocardial infarction with a high thrombus burden. Coron Artery Dis 2012; 23: 497-506. 
38. Kelbæk H, Engstrøm T, Ahtarovski KA, et al. Deferred stent implantation in patients with ST-segment elevation myocardial infarction: a pilot study. Euro Intervention 2013; 8: 1126-33.

39. Freixa X, Belle L, Joseph L, et al. Immediate vs delayed stenting in acute myocardial infarction: a systematic review and meta-analysis. Euro Intervention 2013; 8: 1207-16.

40. Kelbaek H, Hofsten DE, Kober L, Helqvist S, Klovgaard L, Holmvang L, et al. Deferred versus conventional stent implantation in patients with STsegment elevation myocardial infarction (DANAMI 3DEFER): an open-label, randomised controlled trial. Lancet. 2016.

41. Carrick D, Oldroyd KG, McEntegart M, Haig C, Petrie $\mathrm{MC}$, Eteiba $\mathrm{H}$, et al. A randomized trial of deferred stenting versus immediate stenting to prevent no- or slow-reflow in acute ST-segment elevation myocardial infarction (DEFER-STEMI). Journal of the American College of Cardiology. 2014;63(20):2088-98.
42. Kim JS1, Lee HJ1, Woong Yu C2, Kim YM1, Hong SJ1, Park JH1, Choi RK1, Choi YJ1, Park JS1, Kim TH1, Jang HJ1, Joo HJ1, Cho SA1, Ro YM1, Lim DS1. INNOVATION Study (Impact of Immediate Stent Implantation versus Deferred Stent Implantation on Infarct Size and Microvascular Perfusion in Patients with ST-Segment-Elevation Myocardial Infarction). Circ Cardiovasc Interv. 2016 Dec;9(12).

43. Loic Belle, MD; Pascal Motreff, MD, PhD; Lionel Mangin, MD; Grégoire Rangé, MD; Xavier Marcaggi, MD; Antoine Marie, MD; Nadine Ferrier, MD; Olivier Dubreuil, MD; Gilles Zemour, MD; Géraud Souteyrand, MD; Christophe Caussin, MD; Nicolas Amabile, MD, PhD; Karl Isaaz, MD, PhD; Raphael Dauphin, MD; Comparison of Immediate With Delayed Stenting Using the Minimalist Immediate Mechanical Intervention Approach in Acute ST-Segment-Elevation Myocardial Infarction The MIMI Study Circ Cardiovasc Interv. 2016; 9:e003388.

44. Costa JR, Jr, Abizaid A, Dudek D, Silber S, Leon MB, Stone GW. Rationale and design of the MGuard for acute ST elevation reperfusion MASTER trial. Catheter CardiovascInterv. 2013;82(2):184-190. 